\title{
FATORES DETERMINANTES PARA INGRESSO NO MERCADO INTERNACIONAL
}

DOI: http://dx.doi.org/10.18616/pidi10

Jaqueline Rodrigues Pereira - UNESC E-mail: jaquepereira_95@unesc.net Julio Cesar Zilli - UNESC E-mail: zilli42@hotmail.com 


\section{INTRODUÇÃO}

Internacionalização pode ser definida como um processo crescente e continuado de envolvimento das operações de uma empresa com países fora de sua base de origem. Trata-se de um processo contínuo que passa por diversas etapas e que pode expandir consideravelmente os ganhos financeiros da empresa, independentemente de seu porte. A decisão da internacionalização tem sido tema recorrente em diversos segmentos empresariais. Os primeiros exemplos desse processo foram observados em grandes corporações, mas, com o tempo, pequenas e médias empresas têm também considerado essa possibilidade como algo concreto e viável (DAL-SOTO, 2006).

De acordo com Loureiro e Santos (1991), as economias nacionais estão cada vez mais internacionalizadas no que se refere ao comércio e, nesse ramo, fez-se necessária a participação de empresas brasileiras. $O$ ato de internacionalizar a empresa fornece a ela a possibilidade de flexibilidade em sua autonomia econômica, enquanto os meios de sustentabilidade financeira tornam-se ampliados. A partir do momento que se está no mercado internacional, é possível fugir da sazonalidade nacional e beneficiar-se de incentivos governamentais. Há muitos benefícios, mas é importante notar que negociar com outros países é lidar com culturas diferentes, novas normas de negociação, sendo preciso se adaptar para entrar e sobreviver nesse novo mercado (LOUREIRO; SANTOS, 1991).

No contexto brasileiro, há diversas experiências de empresas internacionalizadas. E quanto maior a diversidade econômica maior são as chances de que as empresas optem por um modelo de internacionalização. Esse é o caso do estado de Santa Catarina, uma vez que empresas de diversos setores e portes fizeram essa opção.

Partindo desse contexto, o estudo objetivou analisar os fatores que influenciam a tomada de decisão das empresas exportadoras do sul de Santa Catarina para ingresso no mercado internacional.

Estruturalmente, o capítulo é composto por cinco seções, iniciando pela introdução, seguida pela fundamentação teórica, abarcando temas relacionados à internacionalização das organizações e suas teorias e às estratégias e modelos do processo de internacionalização. Os procedimentos metodológicos que ampararam o desenvolvimento da pesquisa, com ênfase para o delinea- 
mento da pesquisa, definição da área e ou população-alvo e os planos de coleta e análise dos dados fazem parte da seção três. Por fim, destacam-se a apresentação e a discussão dos resultados, as considerações finais e as referências.

\section{INTERNACIONALIZAÇÃO DAS ORGANIZAÇÕES}

O processo de internacionalização pode ser caracterizado pela busca das organizações em comercializar seus bens, produtos e serviços, não somente no mercado doméstico, mas também para outras nações. Esse processo tem início a partir da iniciativa de uma organização em exportar. Nesse primeiro momento, suas vendas começam em pequenas quantidades e, geralmente, para nações semelhantes às suas. Após algum tempo, aumentam suas vendas, procuram por diversas nações, com diversas culturas, podendo ocorrer em algumas delas a abertura de filiais (PORTO, 2014).

Contudo, as empresas não devem ver a internacionalização como uma possível medida desesperada para sair de alguma crise interna ou não da empresa, ou apenas para aumentar as vendas. O ideal é que essa decisão seja tomada como uma forma estratégica pela gestão da empresa (ZILLI; VIEIRA; HEINZEN, 2015). Seguindo esse contexto, nota-se que o processo de internacionalização envolve os resultados estratégicos, os desenvolvimentos emergentes, as oportunidades e as necessidades das empresas (SCHERER; GOMES, 2010). Antes de uma empresa estar efetivamente inserida no mercado internacional, ela deve tomar algumas atitudes que, de acordo com Fleury et al. (2007), são a escolha do país para início das negociações, a sequência de investimentos, a escolha dos produtos a serem comercializados, a logística da fábrica, entre outras.

O processo que caracteriza a internacionalização é composto por nove etapas, descritas no Quadro 1, que são estruturadas com ações específicas, delimitadas com estratégias para abordagem do objetivo da empresa dentro do comércio exterior (ÁVILA, 2009). Porém, nem todas as empresas necessariamente passam por todas as nove etapas para se tornarem globalizadas, pois vai depender da capacidade de crescimento e de evolução que elas possuem (NOSÉ JUNIOR, 2005). 
Quadro 1 - Principais etapas do processo de internacionalização

\begin{tabular}{|c|c|}
\hline ETAPAS & CARACTERÍSTICAS \\
\hline 1a: Exportação Simples & $\begin{array}{l}\text { O processo de internacionalização se inicia para países vizinhos e de } \\
\text { culturas semelhantes. Gerente ou trader viajam para fazer vendas e } \\
\text { abrir mercado. }\end{array}$ \\
\hline $\begin{array}{l}\text { 2a: Instalação de uma } \\
\text { Representação }\end{array}$ & $\begin{array}{l}\text { Instalação de um escritório de representação para o vendedor } \\
\text { internacional da empresa no local de sua atuação. O representante } \\
\text { terá a função de buscar novos negócios e dar continuidade aos já } \\
\text { existentes. }\end{array}$ \\
\hline 3a: Distribuição Comercial & $\begin{array}{l}\text { Evolução do processo de internacionalização, resultado do sucesso } \\
\text { das etapas anteriores. }\end{array}$ \\
\hline $\begin{array}{l}\text { 4a: Abertura de Uma Filial } \\
\text { de Vendas }\end{array}$ & $\begin{array}{l}\text { Organização de um escritório de vendas, ou seja, uma filial que, além } \\
\text { de cuidar das vendas, pode cuidar da assistência técnica, da } \\
\text { distribuição, da propaganda, das relações públicas e governamentais. }\end{array}$ \\
\hline 5ạ: Licenciamento & $\begin{array}{l}\text { Expansão do mercado no local por meio de nomeação de uma } \\
\text { empresa local para distribuição e/ou fabricação de seus produtos sob } \\
\text { autorização. Necessário estabelecer contratos bem definidos. }\end{array}$ \\
\hline 6a: Fabricação Conjunta & $\begin{array}{l}\text { Associação a mercados locais que possuem prestígio nas autoridades } \\
\text { do país e com recursos favoráveis para aumentar a capacidade de } \\
\text { venda com prazos menores. }\end{array}$ \\
\hline $\begin{array}{l}\text { 7ạ: Fabricação Local com } \\
\text { Recursos Próprios }\end{array}$ & $\begin{array}{l}\text { Fabricação de seus produtos, que eram exportados no mercado alvo. } \\
\text { Favorece quanto aos aspectos de nacionalismo e a uma imagem mais } \\
\text { favorável aos consumidores, que se tornam mais confiantes em } \\
\text { relações aos serviços como assistência técnica e garantia do produto. }\end{array}$ \\
\hline $\begin{array}{l}\text { 8a: Multinacionalização da } \\
\text { Empresa }\end{array}$ & $\begin{array}{l}\text { Consequência da capacidade natural da empresa de instalar-se em } \\
\text { vários mercados internacionais. }\end{array}$ \\
\hline $\begin{array}{l}\text { 9a: Globalização da } \\
\text { Empresa }\end{array}$ & $\begin{array}{l}\text { Estar presente de forma marcante em vários países e mercados } \\
\text { mundiais. A empresa usa peças produzidas em várias partes do mundo } \\
\text { para fabricar, vender e distribuir seus produtos. }\end{array}$ \\
\hline
\end{tabular}

Fonte: Elaborado a partir de Nosé Junior (2005, p. 185-188).

Porto (2014, p. 21) informa que há vários motivos que levam as organizações à internacionalização, pois o processo consiste, por um lado, em "[...] uma sequência de interações permanentes entre o conhecimento sobre os mercados e as operações exteriores, e por outro, o compromisso crescente de recursos empregados ou investidos pelas empresas nos mesmos". Os motivos indicados por Porto (2014) são os seguintes: saturação do mercado doméstico; 
exploração de economias de escala; diminuir riscos; prospectar mercados inexplorados; buscar mercados atraentes; captar talentos; obter conhecimentos, incentivos e subsídios do governo.

Quando a empresa opta pela internacionalização, independentemente do motivo, ela obtém algumas vantagens nesse mercado que, segundo Porto (2014), são: economias de escala, vantagens competitivas, acessos a mercados mais amplos, reação à concorrência, entre outras, as quais contribuem significativamente para o crescimento das empresas.

\section{TEORIAS DE INTERNACIONALIZAÇÃO}

As teorias de internacionalização foram desenvolvidas por vários autores com diferentes perspectivas, classificadas em duas linhas de pesquisa: abordagens da internacionalização com base em critérios econômicos e abordagens da internacionalização com base na evolução comportamental. Enquanto na primeira prevalece soluções racionais orientando um caminho de decisões com maiores retornos econômicos, a segunda linha tem base na evolução comportamental e indica que "[...] o processo de internacionalização dependeria das atitudes, percepções e comportamento dos tomadores de decisão, que seriam orientados pela busca da redução de risco nas decisões sobre onde e como expandir." (CARNEIRO; DIB, 2007, p. 4).

Os modelos econômicos têm abordagem que salienta a multinacional como um todo, e o conhecimento estabelecido diz respeito à corporação. De acordo com os modelos econômicos, a decisão de se envolver em operações internacionais é justificada pelo jogo competitivo e, a partir disso, devem ser consideradas as estratégias, a estrutura e o comportamento. Em contrapartida, os modelos comportamentais têm foco principalmente na análise de processo, assim a organização tem sua tomada de decisão por meio de pesquisas de mercado e, como resultado, seleciona uma forma de controle. Esse modelo ainda ressalta que "[...] a internacionalização é um processo composto por passos sequenciais resultantes do conhecimento adquirido." (FLEURY et al., 2007). 


\section{TEORIAS ECONÔMICAS}

O modelo econômico é composto por quatro teorias: a do poder de mercado, a da internacionalização, a do paradigma eclético e a do ciclo de vida do produto.

A primeira admite que as empresas estejam dispostas a aceitar custos e riscos de internacionalização antes da perspectiva do aumento do poder de mercado e de seus respectivos lucros. Esse modelo indica que "[...] a internacionalização da empresa seria o corolário lógico do esgotamento de oportunidades de crescimento no mercado interno no sentido de recomeçar um processo semelhante de crescimento." (CARRASQUEIRA, 2015, p. 62).

A teoria da internacionalização é baseada em caráter intangível, como conhecimentos, tecnologias, capacidades gestoras e de marketing e se assenta em dois princípios: o da empresa, que internalizará as transações até que os custos de transação sejam mais elevados que os que derivam de sua integração organizativa, e o da empresa, que cresce internalizando mercados até o ponto em que os benefícios da internalização compensem os custos (CARRASQUEIRA, 2015).

A terceira teoria, a do paradigma eclético, procura a integração das teorias anteriores, buscando uma explicação para o investimento da empresa no mercado internacional pelos seguintes motivos: busca de novos consumidores, busca de recursos, busca da eficiência e busca de ativos estratégicos (CARRASQUEIRA, 2015). Essa teoria ainda é caracterizada por uma decisão racional, tomada com base em análises dos custos e benefícios de produzir no exterior. Por fim, a teoria do ciclo de vida do produto indica que: "[...] à medida que o produto se padroniza, a elasticidade da demanda diminui. Com isso, as empresas buscam comercializar esse produto em locais onde o mesmo ainda não existe ou está sendo lançado." (PORTO, 2014, p. 26).

\section{TEORIAS COMPORTAMENTAIS}

O modelo comportamental é composto pelas teorias de Uppsala e de redes. A primeira está focada no desenvolvimento de uma empresa individual, por uma perspectiva evolutiva, e na gradual aquisição, integração e utilização 
do conhecimento sobre mercados e operações estrangeiras. Portanto, à medida que aumenta o conhecimento, cresce o comprometimento da empresa com mercados estrangeiros (SCHERER; GOMES, 2010).

A teoria de Uppsala procurou sistematizar o processo de internacionalização, definindo-o como um modelo pelo qual as empresas adotam um processo sequencial de internacionalização, movendo-se em direção a países fisicamente mais próximos, a fim de minimizar incertezas e riscos. É caracterizada por um processo evolutivo lento e gradual (FLEURY et al., 2007). Essa teoria não explica a razão ou a forma pela qual o processo de internacionalização se confirmou, não discute a sequência de estados ou as condições, portanto, há ausência de discussões sobre os fatores que podem influenciar o processo (SCHERER; GOMES, 2010).

Apesar de ser um modelo que busca obter conhecimento para o processo, ele foi criticado em alguns aspectos que, segundo Fleury et al. (2007), foram os seguintes: há diversos trajetos a serem seguidos nos mercados internacionais, onde ele é considerado um modelo ultrapassado, além de ser limitado, explicando mal o processo de internacionalização das empresas.

Diferente da teoria anterior, a de redes, também chamada de Networks, traz o conceito de que os mercados devem ser enfrentados como redes de empresas nas quais a firma irá participar. Essas redes são compostas de relações entre fornecedores, distribuidores, clientes ou agentes públicos tanto no país de origem como no exterior. Decisões relativas à internacionalização são determinadas no interior das redes de relacionamento que as organizações estabelecem. Entende-se que essas redes devem ser vistas como organismos vivos e dinâmicos (CARRASQUEIRA, 2015).

\section{ESTRATÉGIAS E MODELOS DE INTERNACIONALIZAÇÃO}

Uma empresa, quando decide pela internacionalização, depara-se com basicamente três opções de estratégias: atuação isolada, criação de subsidiárias e cooperação com outras empresas. Dessa forma, o Quadro 2 destaca as características de ambas as estratégias, baseadas nos estudos de Brito (1993). 
Quadro 2 - Características das opções de estratégias de internacionalização

\begin{tabular}{|l|l|}
\hline \multicolumn{1}{|c|}{ ESTRATÉGIAS } & \multicolumn{1}{c|}{ CARACTERÍSTICAS } \\
\hline Atuação Isolada & $\begin{array}{l}\text { É caracterizada pelo meio de exportação mais direta, o que torna um meio difícil } \\
\text { para as pequenas empresas utilizarem caso elas não possuam um amplo } \\
\text { conhecimento. }\end{array}$ \\
\hline $\begin{array}{l}\text { Criação de } \\
\text { Subsidiárias }\end{array}$ & $\begin{array}{l}\text { É uma opção que exige maior investimento financeiro, porém se trata de uma } \\
\text { opção estratégica que não se deve desconsiderar. Empresários portugueses têm } \\
\text { adotado essa estratégia, que consiste na "criação ou aquisição de subsidiárias no } \\
\text { estrangeiro". }\end{array}$ \\
\hline $\begin{array}{l}\text { Cooperação com } \\
\text { outras empresas }\end{array}$ & $\begin{array}{l}\text { É a estratégia intermediária entre as duas anteriores, envolve múltiplas } \\
\text { formas, o que reflete em uma grande flexibilidade negocial. }\end{array}$ \\
\hline
\end{tabular}

Fonte: Adaptado de Brito (1993, p. 4-7).

As estratégias de internacionalização ainda podem ser classificadas em dois grupos: as estratégias de entrada em mercados internacionais e as estratégias de marketing mix internacional (ZILLI; VIEIRA; HEINZEN, 2015). As estratégias de entrada e operação em mercados são ações que visam introduzir um novo negócio ou empresa no mercado internacional, que podem ser: joint ventures, investimento direto, mergers, acquisitions, franquias internacionais, exportação e importação direta e indireta. No marketing mix internacional, as empresas podem optar por comercializar seus produtos e serviços de maneira padrão ou optar por adaptá-las (KUAZAQUI; LISBOA, 2009).

Dentre as diversas estratégias citadas acima, cada qual oferece um grau de controle à empresa, classificado como sendo baixo (estratégia de exportação indireta) e alto (abertura de subsidiárias). Os métodos que disponibilizam maior grau de controle são os que exigem compromissos de recursos substanciais e envolvem muitos riscos (KOBATE; HELSEN, 2000). Apesar das diversas estratégias, os dados divulgados por Fleury, Meira e Schmidt (1981, p. 2) mostram que "[...] apenas $19 \%$ das empresas brasileiras produtoras e exportadoras de manufaturados praticam a exportação direta, enquanto as restantes $81 \%$ exportam apenas indiretamente". 


\section{METODOLOGIA}

Sob a ótica de Sampieri, Callado e Lucio (2013), este estudo se caracteriza como uma pesquisa descritiva quanto aos fins de investigação. Esse método foi utilizado na pesquisa porque foi apresentada uma série de informações obtidas a partir de um levantamento de dados feito nas empresas exportadoras de Criciúma e região. Quanto aos meios de investigação, trata-se de uma pesquisa bibliográfica e uma pesquisa de campo. A pesquisa bibliográfica foi necessária para um maior conhecimento do tema abordado e auxílio para o embasamento teórico, enquanto que a pesquisa de campo foi realizada com a aplicação de um questionário nas empresas exportadoras objeto do estudo.

A pesquisa projetou como população 25 empresas exportadoras que compõem a região sul de Santa Catarina, considerando o faturamento no mercado externo, na faixa de US\$ 1 a 10 milhões e US\$ 10 a 50 milhões, como pode ser observado na Tabela 1. 
Tabela 1 - Prospecção da população de empresas exportadoras do sul de Santa Catarina

\begin{tabular}{|c|c|c|}
\hline MUNICÍPIO & EMPRESAS & FAIXA FATURAMENTO \\
\hline NOVA VENEZA & JBS AVES LTDA & Entre US\$ 10 e 50 milhões \\
\hline NOVA VENEZA & AGROVÊNETO S.A. - INDÚSTRIA DE ALIMENTOS & Entre US\$ 10 e 50 milhões \\
\hline COCAL DO SUL & ELIANE S/A - REVESTIMENTOS CERÂMICOS & Entre US\$ 10 e 50 milhões \\
\hline CRICIÚMA & PLASSON DO BRASIL LTDA & Entre US\$10 e 50 milhões \\
\hline ORLEANS & LIBRELATO S.A. IMPLEMENTOS RODOVIÁRIOS & Entre US\$ 1 e 10 milhões \\
\hline IÇARA & COLORMINAS COLORÍFICIO E MINERAÇÃO S/A & Entre US\$ 1 e 10 milhões \\
\hline CRICIÚMA & ANGELGRES REVESTIMENTOS CERÂMICOS LTDA & Entre US\$ 1 e 10 milhões \\
\hline CRICIÚMA & CECRISA REVESTIMENTOS CERÂMICOS S.A & Entre US\$ 1 e 10 milhões \\
\hline IÇARA & SMALTICERAM UNICER DO BRASIL LTDA & Entre US\$ 1 e 10 milhões \\
\hline MORRO DA FUMAÇA & MOLIZA REVESTIMENTOS CERÂMICOS LTDA & Entre US\$ 1 e 10 milhões \\
\hline CRICIÚMA & PISOFORTE REVESTIMENTOS CERÂMICOS LTDA & Entre US\$ 1 e 10 milhões \\
\hline MORRO DA FUMAÇA & ESMALGLASS DO BRASIL FRITAS ESM. E COR. CERÂMICOS LTDA & Entre US\$ 1 e 10 milhões \\
\hline IÇARA & FARBEN S/A INDÚSTRIA QUÍMICA & Entre US\$ 1 e 10 milhões \\
\hline CRICIÚMA & GABRIELLA REVESTIMENTOS CERÂMICOS LTDA & Entre US\$ 1 e 10 milhões \\
\hline NOVA VENEZA & METALÚRGICA DS LTDA & Entre US\$ 1 e 10 milhões \\
\hline CRICIÚMA & MILANO ESTRUTURAS METÁLICAS LTDA & Entre US\$ 1 e 10 milhões \\
\hline CRICIÚMA & CERÂMICA ARTÍSTICA GISELI LTDA & Entre US\$ 1 e 10 milhões \\
\hline IÇARA & MINAMEL AGROINDÚSTRIA LTDA & Entre US\$ 1 e 10 milhões \\
\hline CRICIÚMA & CANGURU S/A INDÚSTRIA E COMÉRCIO DE PRODUTOS PLÁSTICOS & Entre US\$ 1 e 10 milhões \\
\hline ICARA & TORRECID DO BRASIL FRITAS ESMALTES E CORANTES LTDA & Entre US\$ 1 e 10 milhões \\
\hline CRICIUMA & MANCHESTER QUIMICA DO BRASIL S.A & Entre US\$ 1 e 10 milhões \\
\hline SIDEROPOLIS & RESICOLOR INDÚSTRIA DE PRODUTOS QUIMICOS LTDA & Entre US\$ 1 e 10 milhões \\
\hline CRICIUMA & BEL EXPORT HIDRODINAMICA INDÚSTRIA DE BOMBAS HIDRAULICA & Entre US\$ 1 e 10 milhões \\
\hline CRICIUMA & ICON ESTAMPOS E MOLDES S/A & Entre US\$ 1 e 10 milhões \\
\hline FORQUILHINHA & HENCE DO BRASIL LTDA. & Entre US\$ 1 e 10 milhões \\
\hline
\end{tabular}

Fonte: Adaptada de MDIC (BRASIL, s.d.).

Com relação à amostra, Appolinário (2006) argumenta que ela é um subconjunto extraído da população-alvo e a representa, supondo-se que tudo que será concluído a partir dessa amostra é valido para a população como um todo. Assim, a amostra foi composta por 14 empresas, que efetivamente participaram da pesquisa, respondendo a um questionário enviado para os responsáveis pelos processos de exportação, caracterizando-se, então, como uma amostra não probabilística. 
A obtenção dos dados foi realizada por meio de dados primários, com uma investigação direta e junto à amostra de empresas exportadoras do sul de Santa Catarina. Quanto à técnica de coleta de dados, usou-se a quantitativa, por meio da aplicação de um questionário, pois este foi o instrumento que melhor se adequou aos objetivos deste estudo.

Os dados se caracterizam por uma análise essencialmente qualitativa.

\section{APRESENTAÇÃO E DISCUSSÃO DOS RESULTADOS}

Esta seção destaca a caracterização das empresas no mercado interno e externo, fatores para o ingresso internacional, estratégias utilizadas, bem como as barreiras organizacionais e externas no processo de internacionalização.

\section{CARACTERIZAÇÃO DAS EMPRESAS NO MERCADO INTERNO}

O primeiro aspecto da pesquisa se deu pela caracterização das empresas no mercado interno, para, dessa forma, ser possível identificar dentro das 14 respostas seus respectivos setores de atuação, localização, data de fundação, porte, composição do capital e forma de administração. Identificou-se que na região os setores que estão mais representados em quantidade são os de metalmecânico e revestimentos cerâmicos, seguidos pelo químico, polímero e agroindustrial. Os dois primeiros setores citados representaram, cada um, 28,57\%, e os demais, respectivamente, representaram: $21,43 \%, 14,29 \%$ e 7,14\%. Nos Quadros 3 e 4 é possível identificar características do mercado interno correspondentes a cada setor. 
Quadro 3 - Caracterização do mercado interno (parte 1)

\begin{tabular}{|c|c|c|c|c|c|c|}
\hline \multirow{2}{*}{ SETOR } & \multirow{2}{*}{ QUANT. } & \multirow{2}{*}{ LOCALIZAÇÃO } & \multirow{2}{*}{ FUNDAÇÃO } & \multirow{2}{*}{ PORTE } & \multicolumn{2}{|c|}{ TOTAL } \\
\hline & & & & & $\mathbf{F}$ & $\%$ \\
\hline \multirow{4}{*}{ Metal Mecânico } & 1 & Siderópolis & 2007 & Médio & \multirow{4}{*}{4} & \multirow{4}{*}{28,57} \\
\hline & 1 & Nova Veneza & 2011 & Micro & & \\
\hline & \multirow{2}{*}{2} & \multirow{2}{*}{ Criciúma } & 1982 & Médio & & \\
\hline & & & 1978 & Grande & & \\
\hline \multirow{4}{*}{$\begin{array}{l}\text { Revestimentos } \\
\text { cerâmicos }\end{array}$} & 1 & Urussanga & 1953 & Médio & \multirow{4}{*}{4} & \multirow{4}{*}{28,57} \\
\hline & \multirow{3}{*}{3} & \multirow{3}{*}{ Criciúma } & 1972 & Médio & & \\
\hline & & & 1986 & Médio & & \\
\hline & & & 1986 & $\begin{array}{l}\text { Pequen } \\
\text { a }\end{array}$ & & \\
\hline \multirow{3}{*}{ Químico } & \multirow{2}{*}{2} & \multirow{2}{*}{ Criciúma } & 1999 & \multirow{3}{*}{ Médio } & \multirow{3}{*}{3} & \multirow{3}{*}{21,43} \\
\hline & & & 1986 & & & \\
\hline & 1 & Içara & 1991 & & & \\
\hline \multirow[t]{2}{*}{ Polímeros } & \multirow[t]{2}{*}{2} & \multirow[t]{2}{*}{ Orleans } & 2006 & $\begin{array}{l}\text { Pequen } \\
\text { a }\end{array}$ & \multirow[t]{2}{*}{2} & \multirow[t]{2}{*}{14,29} \\
\hline & & & 2003 & Médio & & \\
\hline Agroindustrial & 1 & Nova Veneza & 1996 & Grande & 1 & 7,14 \\
\hline TOTAL & & & & & 14 & 100,00 \\
\hline
\end{tabular}

Fonte: Elaboração própria a partir de dados da pesquisa (2016).

Nota-se que a maioria das empresas é caracterizada como de porte médio, representando 64,29\% das entrevistadas, pois, segundo o SEBRAE (2006), possui entre 100 a 499 funcionários atuando em sua indústria. No entanto, é possível identificar que não são somente as grandes e médias empresas que estão ingressando no comércio internacional. Pequenas e microempresas estão buscando novos mercados e possibilidades de crescimento. A microempresa identificada na coleta de dados está localizada no município de Nova Veneza e pertence ao setor metalmecânico, o qual é forte. Segundo o SEBRAE (2010), em Nova Veneza, apenas cinco empresas estão ativas no mercado internacional por meio das exportações. 
Em um segundo momento, ainda caracterizando as empresas dentro do mercado interno, procurou-se analisar como está estruturado o capital das empresas e sua forma de administração, o que é possível observar no Quadro 4.

Quadro 4 - Caracterização do mercado interno (parte 2)

\begin{tabular}{|c|c|c|c|c|c|}
\hline \multirow{2}{*}{ SETOR } & \multirow{2}{*}{ QUANT. } & \multirow{2}{*}{ COMPOSIÇÃO DO CAPITAL } & \multirow{2}{*}{$\begin{array}{c}\text { FORMA DE } \\
\text { ADMINISTRAÇÃO }\end{array}$} & \multicolumn{2}{|c|}{ TOTAL } \\
\hline & & & & $\mathbf{F}$ & $\%$ \\
\hline \multirow{3}{*}{ Metal Mecânico } & 1 & $100 \%$ Nacional. & Familiar & \multirow{3}{*}{4} & \multirow{3}{*}{28,57} \\
\hline & 2 & Misto: majoritariamente nacional. & Mista & & \\
\hline & 1 & $100 \%$ Nacional. & Profissionalizada & & \\
\hline \multirow{4}{*}{$\begin{array}{l}\text { Revestimentos } \\
\text { cerâmicos }\end{array}$} & 1 & Misto: majoritariamente nacional. & Profissionalizada & \multirow{4}{*}{4} & \multirow{4}{*}{28,57} \\
\hline & \multirow{3}{*}{3} & Misto: majoritariamente nacional. & Mista & & \\
\hline & & 100\% Nacional. & Familiar & & \\
\hline & & $100 \%$ Nacional. & Profissionalizada & & \\
\hline \multirow{2}{*}{ Químico } & 2 & \multirow{2}{*}{ 100\% Nacional. } & Profissionalizada & \multirow{2}{*}{3} & \multirow{2}{*}{21,43} \\
\hline & 1 & & Familiar & & \\
\hline Polímeros & 2 & $100 \%$ Nacional. & Familiar & 2 & 14,29 \\
\hline Agroindustrial & 1 & Misto: majoritariamente nacional. & Profissionalizada & 1 & 7,14 \\
\hline TOTAL & & & & 14 & 100,00 \\
\hline
\end{tabular}

Fonte: Elaboração própria a partir de dados da pesquisa (2016).

A partir do Quadro 4, é possível constatar que a composição de capital predominante é nacional, ou seja, os recursos e/ou bens adquiridos para empresa não possuem a participação dos resultados obtidos na inserção internacional. Enquanto $64,29 \%$ das empresas compõem seu capital de somente frutos nacionais, 35,71\% já possuem uma composição mista, porém majoritariamente nacional, ou seja, a participação estrangeira é ainda muito pequena. Nenhuma das entrevistas apresenta predominância estrangeira.

Ao investigar as formas de administração das empresas, nota-se que $42,86 \%$ delas é de forma profissionalizada, portanto, a maioria busca o mercado profissional adequado para atuar em áreas específicas dentro da empresa. Dentro desse percentual, os portes que integram são tanto pequeno e médio 
quanto grande. A forma de administração familiar, no entanto, ainda é muito forte, composta, neste estudo, por $35,71 \%$ das respostas, enquanto a forma mista (familiar e profissionalizada) corresponde a $21,43 \%$.

A seguir, apresenta-se uma análise voltada para a caracterização das empresas no mercado externo.

\section{CARACTERIZAÇÃO DAS EMPRESAS NO MERCADO EXTERNO}

No primeiro momento de caracterização das empresas no mercado externo, buscou-se investigar as seguintes questões: mercados internacionais de atuação, tempo de atuação e os principais produtos exportados. A partir do Quadro 5, que traz todas essas informações, observou-se que a maioria negocia com as Américas, com destaque para a América do Sul, onde 92,86\% das empresas estão ativas.

Verifica-se, também, que $42,86 \%$ das empresas não se limitaram a atuar em um único lugar, buscando outros lugares para inserir seu produto, entre eles, além das Américas, África, Europa e Ásia. As empresas que procuraram explorar mais mercados possuem um tempo de atuação maior que cinco anos. Dentre estas que negociam com mais de um mercado, $21,43 \%$ possuem tempo de atuação de 15 a 20 anos, portanto, possuem vasta experiência para lidar com diferentes culturas e costumes dos países parceiros. No entanto, $14,29 \%$ delas estão há mais tempo, em torno de 20 a 25 anos, enquanto somente 7,14\% apresentam de 5 a 10 anos de atuação. Isso indica que não é somente a experiência em mercados que atrai a empresa a expandir suas negociações internacionais, há diversos fatores envolvidos que serão discutidos nos tópicos seguintes. 
Quadro 5 - Caracterização do mercado externo (parte 1)

\begin{tabular}{|c|c|c|c|c|c|c|}
\hline \multirow{2}{*}{ SETOR } & \multirow{2}{*}{ QUANTIDADE } & \multirow{2}{*}{$\begin{array}{l}\text { MERCADOS } \\
\text { INTERNACIONAIS }\end{array}$} & \multirow{2}{*}{$\begin{array}{l}\text { TEMPO } \\
\text { ATUAÇÃO }\end{array}$} & \multirow{2}{*}{$\begin{array}{l}\text { PRODUTOS } \\
\text { EXPORTADOS }\end{array}$} & \multicolumn{2}{|c|}{ TOTAL } \\
\hline & & & & & $\mathbf{F}$ & $\%$ \\
\hline \multirow{4}{*}{$\begin{array}{l}\text { Metal } \\
\text { Mecânico }\end{array}$} & 1 & América do Sul & Até 5 anos & Bomba de Vácuo & \multirow{4}{*}{4} & \multirow{4}{*}{28,57} \\
\hline & 1 & América do Sul & De 5 a 10 anos & Luminárias & & \\
\hline & 1 & $\begin{array}{l}\text { América do } \\
\text { Sul/Central/Norte, África } \\
\text { e Europa }\end{array}$ & De 5 a 10 anos & $\begin{array}{l}\text { Motores e Bombas } \\
\text { Hidráulicas }\end{array}$ & & \\
\hline & 1 & América do Sul/Norte & De 20 a 25 anos & Autopeças & & \\
\hline \multirow{4}{*}{$\begin{array}{l}\text { Revestimentos } \\
\text { Cerâmicos }\end{array}$} & 1 & $\begin{array}{l}\text { América do Sul e } \\
\text { América Central }\end{array}$ & De 15 a 20 anos & $\begin{array}{l}\text { Peças especiais - faixas, } \\
\text { rodapés }\end{array}$ & \multirow{4}{*}{4} & \multirow{4}{*}{28,57} \\
\hline & 1 & $\begin{array}{l}\text { América do } \\
\text { Sul/Central/Norte e } \\
\text { África. }\end{array}$ & De 20 a 25 anos & $\begin{array}{l}\text { Revestimentos } \\
\text { Cerâmicos }\end{array}$ & & \\
\hline & 1 & $\begin{array}{l}\text { América do } \\
\text { Sul/Central/Norte }\end{array}$ & De 15 a 20 anos & $\begin{array}{l}\text { Revestimentos } \\
\text { Cerâmicos Esmaltados }\end{array}$ & & \\
\hline & 1 & América do Sul & De 30 a 35 anos & Estampos e Moldes & & \\
\hline \multirow{3}{*}{ Químico } & 1 & América do Sul & De 5 a 10 anos & $\begin{array}{l}\text { Produtos Químicos para } \\
\text { Cerâmica }\end{array}$ & \multirow{3}{*}{3} & \multirow{3}{*}{21,43} \\
\hline & 1 & América do Sul & De 15 a 20 anos & $\begin{array}{l}\text { Tintas e complementos } \\
\text { da linha automotiva }\end{array}$ & & \\
\hline & 1 & América do Sul & De 15 a 20 anos & Tintas e Vernizes & & \\
\hline \multirow[t]{2}{*}{ Polímeros } & 1 & América do Sul & Até 5 anos & Descartáveis Plásticos & \multirow[t]{2}{*}{2} & \multirow[t]{2}{*}{14,29} \\
\hline & 1 & América do Sul & Até 5 anos & Filmes Plásticos & & \\
\hline Agroindustrial & 1 & África, Europa e Ásia & De 15 a 20 anos & $\begin{array}{l}\text { Cortes congelados de } \\
\text { frango }\end{array}$ & 1 & 7,14 \\
\hline TOTAL & & & & & 14 & 100,00 \\
\hline
\end{tabular}

Fonte: Elaboração própria a partir de dados da pesquisa (2016).

Em relação aos principais produtos exportados atualmente por essas 14 empresas, cada qual possui o seu diferencial, o seu produto-chave, porém, conforme indicado no Quadro 6, 85,71\% exportam produtos manufaturados, ou seja, produtos cuja fabricação utiliza os recursos da empresa. 
Quadro 6 - Caracterização do mercado externo (parte 2)

\begin{tabular}{|c|c|c|c|c|c|c|}
\hline \multirow[b]{2}{*}{ SETOR } & \multirow[b]{2}{*}{ QUANTIDADE } & \multirow{2}{*}{$\begin{array}{c}\text { CATEGORIA } \\
\text { DOS PRODUTOS }\end{array}$} & \multirow{2}{*}{$\begin{array}{c}\text { \% DA } \\
\text { EXPORTAÇÃO } \\
\text { NO } \\
\text { FATURAMENTO }\end{array}$} & \multirow{2}{*}{$\begin{array}{c}\text { \% DA } \\
\text { EXPORTAÇÃO } \\
\text { NA PRODUÇÃO } \\
\text { TOTAL }\end{array}$} & \multicolumn{2}{|c|}{ TOTAL } \\
\hline & & & & & $\mathbf{F}$ & $\%$ \\
\hline \multirow{4}{*}{$\begin{array}{l}\text { Metal } \\
\text { Mecânico }\end{array}$} & 1 & Manufaturados & Até $10 \%$ & Até $10 \%$ & \multirow{4}{*}{4} & \multirow{4}{*}{28,57} \\
\hline & 1 & Manufaturados & Até $10 \%$ & Até $10 \%$ & & \\
\hline & 1 & Manufaturados & De $20 \%$ a $30 \%$ & De $20 \%$ a $30 \%$ & & \\
\hline & 1 & Manufaturados & De $10 \%$ a $20 \%$ & Até $10 \%$ & & \\
\hline \multirow{4}{*}{$\begin{array}{l}\text { Revestimentos } \\
\text { Cerâmicos }\end{array}$} & 1 & Manufaturados & De $20 \%$ a $30 \%$ & De $20 \%$ a $30 \%$ & \multirow{4}{*}{4} & \multirow{4}{*}{28,57} \\
\hline & 1 & Manufaturados & Até $10 \%$ & De $10 \%$ a $20 \%$ & & \\
\hline & 1 & Manufaturados & Até $10 \%$ & Até $10 \%$ & & \\
\hline & 1 & Manufaturados & De $20 \%$ a $30 \%$ & De $20 \%$ a $30 \%$ & & \\
\hline \multirow{3}{*}{ Químico } & 1 & Manufaturados & Até $10 \%$ & De $10 \%$ a $20 \%$ & \multirow{3}{*}{3} & \multirow{3}{*}{21,43} \\
\hline & 1 & Manufaturados & Até $10 \%$ & Até $10 \%$ & & \\
\hline & 1 & Manufaturados & Até $10 \%$ & Até $10 \%$ & & \\
\hline \multirow[t]{2}{*}{ Polímeros } & 1 & $\begin{array}{l}\text { Semimanufaturados } \\
\text { e Manufaturados }\end{array}$ & De $10 \%$ a $20 \%$ & De $10 \%$ a $20 \%$ & \multirow[t]{2}{*}{2} & \multirow[t]{2}{*}{14,29} \\
\hline & 1 & Primários & De $10 \%$ a $20 \%$ & De $10 \%$ a $20 \%$ & & \\
\hline Agroindustrial & 1 & Primários & Acima de $50 \%$ & Acima de $50 \%$ & 1 & 7,14 \\
\hline TOTAL & & & & & 14 & 100,00 \\
\hline
\end{tabular}

Fonte: Elaboração própria a partir de dados da pesquisa (2016).

De acordo com dados do MDIC (BRASIL, 2015), a exportação desses manufaturados eleva a balança comercial brasileira para superavit, pois essa categoria vem apresentando crescimento, tanto que em setembro de 2015 foi registrado um aumento de $25,5 \%$ nas suas vendas externas.

Em relação à representatividade da exportação no faturamento total da empresa, é visível que ainda possui uma pequena representatividade, porque, para a maioria das empresas, o percentual não passa dos $10 \%$, o que se repete na representatividade da exportação na produção total da empresa, pois $35,71 \%$ das empresas possuem representatividade de até $10 \%$ tanto no faturamento quanto na produção total e somente $7,14 \%$ (uma empresa) possuem representatividade de ambos os aspectos acima de $50 \%$, uma vez que esta empresa é caracterizada por ser do setor agroindustrial, de grande porte, exportadora de produtos primários para os mercados da África, Ásia e Europa. 
A partir desses índices, é possível identificar que as empresas possuem capacidade de aumentar essas representações, pois podem procurar novos mercados para destinar uma porcentagem maior de seus produtos para o estrangeiro e, consequentemente, aumentar o faturamento, porque, na sua maioria, elas estão exportando produtos manufaturados que possuem valor agregado maior que os semimanufaturados e primários.

A seguir, apresenta-se uma análise voltada para os principais fatores que foram determinantes na inserção internacional das empresas.

\section{FATORES DETERMINANTES NA INSERÇÃO INTERNACIONAL}

Para melhor visualização dos dados obtidos, esta seção apresenta alguns gráficos conforme as questões feitas às empresas. O primeiro ponto observado foi o surgimento da primeira iniciativa e/ou desejo de iniciar transações internacionais. Entre as alternativas encontravam-se as seguintes opções: i) a empresa foi procurada por um cliente em potencial; ii) a empresa tomou a iniciativa de analisar o mercado externo e iii) o processo de inserção internacional estava no planejamento estratégico.

Conforme observa-se na Figura 1, 50\% das empresas tiveram como fator determinante para realizar sua inserção no mercado externo as análises de mercado, pois a própria empresa foi analisar e verificar como o mercado melhor aceitaria seus produtos. Apenas $21,43 \%$, ou seja, três empresas tinham como planejamento estratégico a inserção no mercado internacional, enquanto $28,57 \%$ apenas reagiram às oportunidades quando foram procuradas por clientes em potencial que se interessaram por seus produtos.

Essas empresas que reagiram às oportunidades obtêm, segundo Fleury, Meira e Schmidt (1981), em geral, informações informais, básicas e bastante incompletas para as suas tomadas de decisão, portanto, essas decisões são baseadas em estratégias de satisfação e condições mínimas. 
Figura 1 - Primeira iniciativa/desejo de iniciar transações internacionais

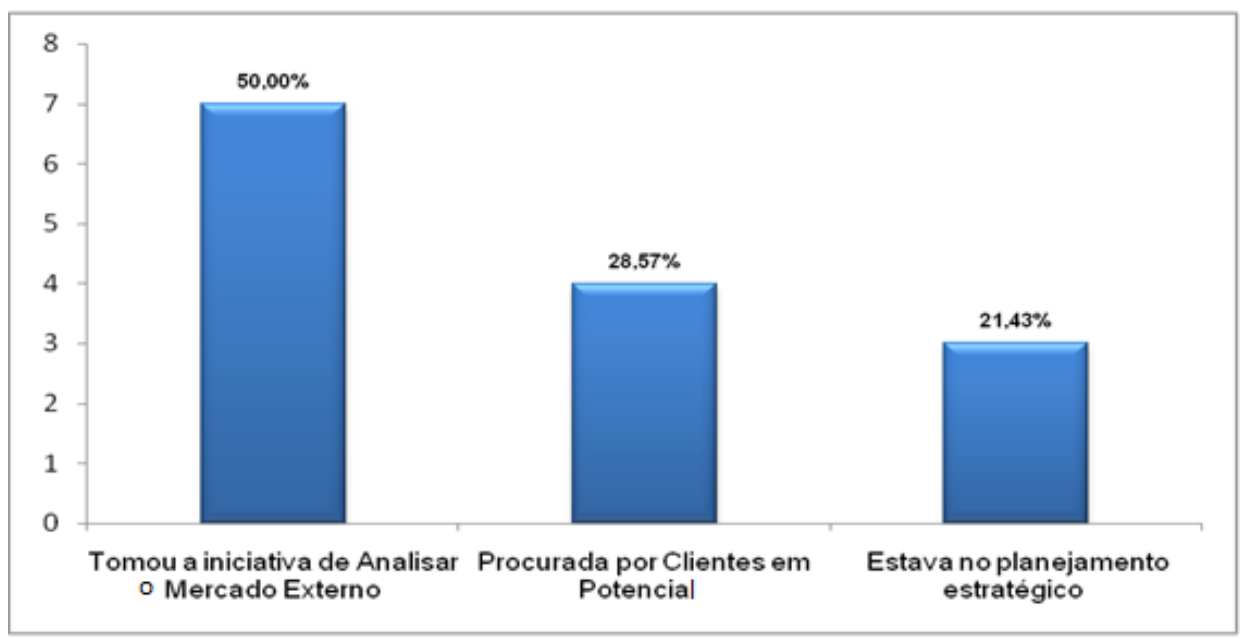

Fonte: Elaboração própria a partir de dados da pesquisa (2016).

Ao analisar o segundo ponto, que se trata dos principais motivos que levaram as empresas a iniciarem suas negociações internacionais, vê-se que, de acordo com a Figura 2, a sua maioria, correspondente a 15,87\%, o principal motivo foi a estratégia de desenvolvimento da empresa, seguida de vantagens competitivas $(14,29 \%)$ e da busca por diversidades de mercados $(12,70 \%)$ para aumentar a produtividade e, consequentemente, os lucros $(11,11 \%)$, o que resulta em $50 \%$ que analisaram o mercado exterior e/ou aqueles que tinham como planejamento estratégico a inserção.

Observa-se, ainda, a partir da Figura 2, que muitas empresas encaram a exportação de uma forma passiva, reagindo a estímulos internos e externos, como pedidos inesperados $(7,94 \%)$, incentivos governamentais $(7,94 \%)$, crise no mercado interno $(3,17 \%)$ e excedentes de produção $(1,59 \%)$.

O terceiro e último ponto que caracteriza os fatores determinantes na inserção internacional das empresas é o motivo que as levaram a exportar para o mercado de escolha. Vale lembrar que tanto no segundo ponto quanto no terceiro, as empresas tinham a possibilidade de escolher mais de um item determinante. 
Figura 2 - Principais motivos para iniciar as negociações internacionais

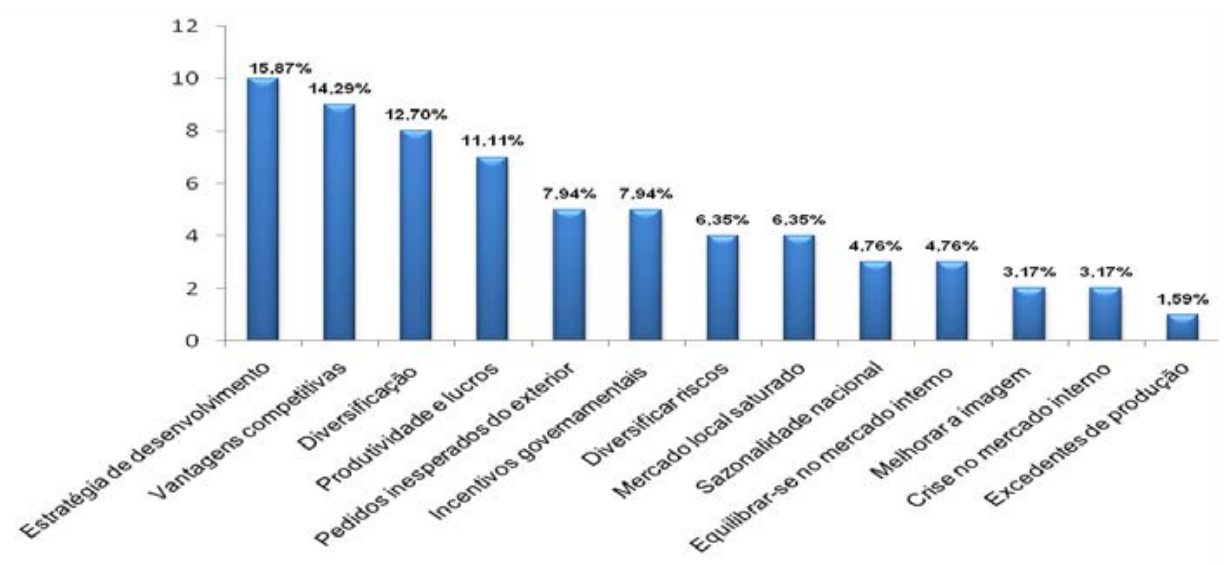

Fonte: Elaboração própria a partir de dados da pesquisa (2016).

Segundo Fleury, Meira e Schmidt (1981), os problemas básicos para a escolha de mercados consistem em coletar as informações necessárias sobre um grande número de mercados, além da necessidade de haver o envolvimento de muitas pessoas com conhecimentos e habilidades diversas para, juntas, tomarem a melhor decisão para a empresa.

Entre os motivos de escolha das quatorze empresas da região da AMREC destacam-se a oportunidade boa e/ou lucrativa e uma demanda visível para seus produtos, que, juntas, representam $50 \%$ dos motivos de escolha sobre os mercados internacionais, o que é possível observar na Figura 3.

Os motivos: concorrentes já comercializavam com o mercado $(5,56 \%)$ e mercado-alvo próximo e com cultura semelhante (16,67\%), o que leva a suspeitar que havia a existência de um processo decisório de internacionalização racional, pois, partindo da hipótese de que as empresas não tinham informações suficientes para tomar suas decisões, foi necessário analisar indicativos internos e geográficos como um conjunto de alternativas para escolher um mercado que melhor se encaixasse aos seus perfis empresariais e ao interesse empresarial daquele momento. 
Figura 3 - Motivos de escolha do mercado internacional

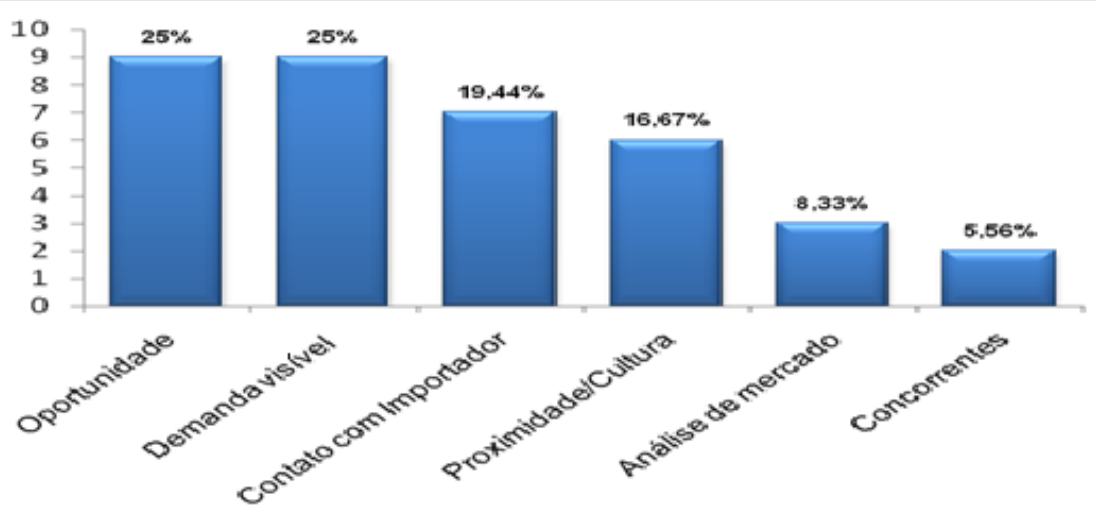

Fonte: Elaboração própria a partir de dados da pesquisa (2016).

Os demais motivos citados denotam um processo decisório mais elaborado, pois analisam outros indicativos além do fato de, em alguns casos, a empresa brasileira já ter algum contato com a empresa do seu futuro cliente. Levanta a suspeita também de que mais de um mercado tenha sido considerado uma opção fortuita.

A seguir, apresenta-se uma análise voltada para as estratégias utilizadas na inserção internacional.

\section{ESTRATÉGIAS NA INSERÇÃO INTERNACIONAL}

Com a presente pesquisa, buscou-se verificar como as empresas do Sul escolheram as suas estratégias para inserção internacional. De forma geral, as empresas puderam responder assinalando uma opção de estratégia, a mais relevante, em cada ponto abordado.

No primeiro momento, foi levantado um questionamento para identificar se foi realizada alguma abordagem de pré-seleção de mercados e/ou clientes antes de iniciar as transações no mercado internacional, conforme é possível observar na Figura 4. Verificou-se que $10,53 \%$ não realizaram nenhuma pré-seleção, enquanto $26,32 \%$ apenas reagiram às oportunidades que surgiram. Conclui-se, então, que a maioria das empresas, em um primeiro momento, não se envolveram tanto no processo, considerando, talvez, só mais um meio de venda propício para aumentar sua lucratividade. 
Em contrapartida, outras empresas se preocuparam em escolher um mercado que melhor se adequasse às suas condições naquele momento, portanto, analisaram o grau de concorrência $(15,79 \%)$, o nível de desenvolvimento do país $(10,53 \%)$, a pesquisa em dados já publicados $(10,53 \%)$ e o tamanho do mercado (26,32\%). Pressupõe-se, a partir desses dados, um maior envolvimento da empresa e a intenção de inserção planejada.

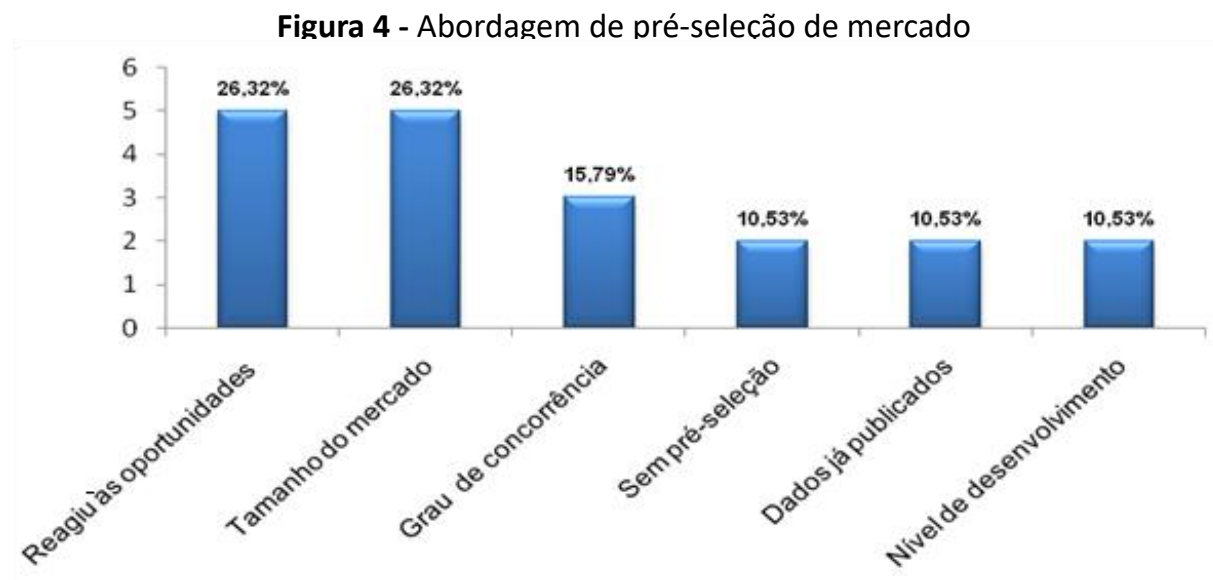

Fonte: Elaboração própria a partir de dados da pesquisa (2016).

De acordo com Motta (2007), o processo de internacionalização pode envolver considerações amplas sobre estratégias e comportamentos da economia ao se comparar com possíveis investimentos no mercado interno. Portanto, a entrada em mercados externos pode envolver diferentes formas de estratégia, as quais são visíveis na Figura 5, de acordo com as escolhas das empresas da região da AMREC.

Nota-se, a partir da Figura 5, que 56,52\% das empresas optaram pela exportação direta que consiste, segundo Nosé Junior (2005), no total controle das operações pela empresa exportadora em todas as etapas do processo. A partir disso, pode-se concluir que as empresas foram atrás de conhecimentos e/ou profissionais que tinham tal conhecimento para adentrar o mercado internacional. No entanto, de acordo com Ávila (2009), esse método consiste em altos riscos para a organização devido ao custo que lhe é necessário, mas, em contrapartida, permite que o retorno da lucratividade seja maior. Ávila (2009) também informa que nesse método as operações normalmente ocorrem por meio de um agente ou de um representante internacional comissionado. 
Figura 5 - Estratégias utilizadas nas operações internacionais

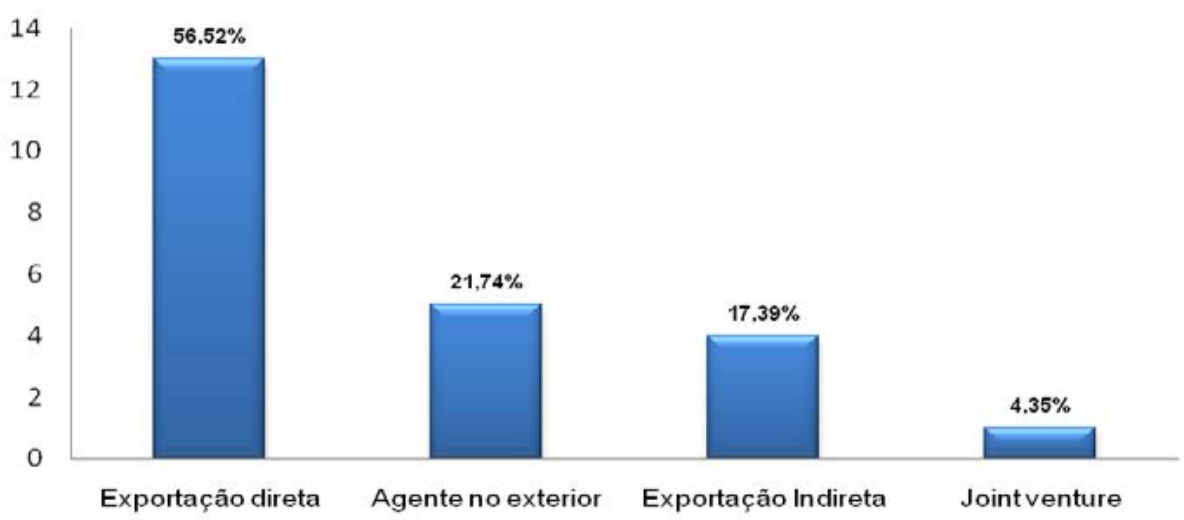

Fonte: Elaboração própria a partir de dados da pesquisa (2016).

Além de uma estratégia bem escolhida para as empresas e de profissionais adequados para cuidar de tal processo, a empresa precisa adotar alguns procedimentos para decidir o mercado, de modo a vir a conhecê-lo. Sem tais conhecimentos, as empresas podem vir a cometer "gafes" e a perder negociações, pois cada região e cada país possuem sua cultura distinta, suas leis e formas de negociar.

Abaixo, na Figura 6, é possível observar os procedimentos que as empresas do presente estudo adotaram. Constata-se, portanto, que a grande maioria, 34,78\%, optou por escolher participar e/ou realizar visitas em feiras internacionais.

As empresas que adotaram como procedimentos consultas e/ou contatos informais $(30,43 \%)$ ou apenas intuição $(4,35 \%)$ tomaram suas decisões em conhecimentos que estavam dentro de seu domínio, portanto, suas análises foram subjetivas. Já as demais empresas que optaram pelos demais procedimentos visíveis, na Figura 6 procuraram por procedimentos mais explícitos, ou seja, baseados em informações mais concretas que lhes ofereceram maior confiança ao tomarem suas decisões. 
Figura 6 - Procedimentos adotados para tomada de decisão de mercado

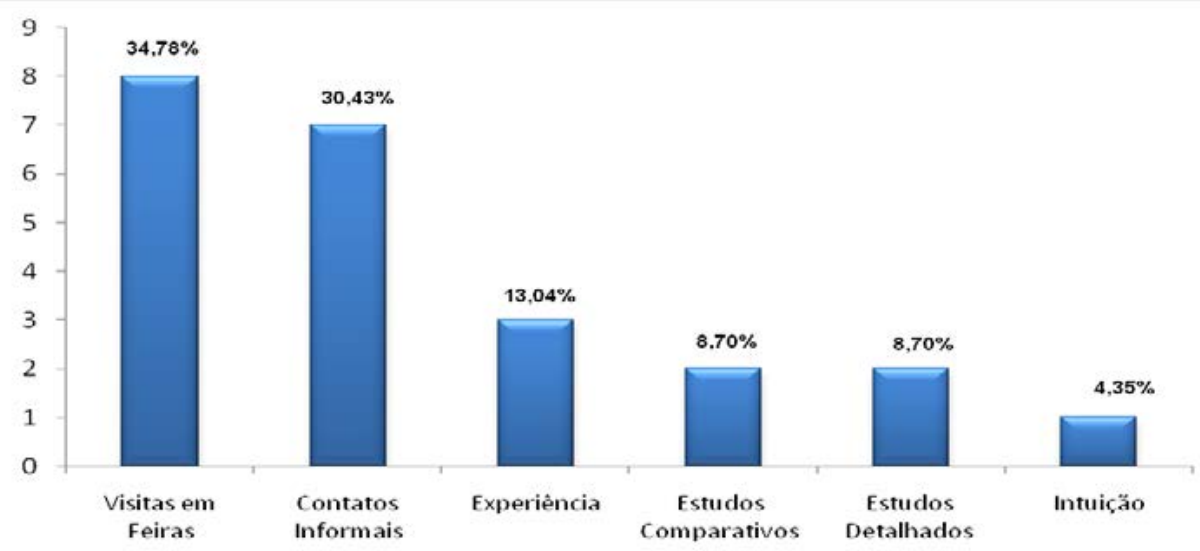

Fonte: Elaboração própria a partir de dados da pesquisa (2016).

Para uma tomada de decisão mais segura e concreta, a empresa vai atrás de algumas informações, as quais fazem com que a empresa opte ou não por negociar com determinado mercado. Logo, as informações específicas utilizadas ao longo do processo decisório foram reunidas em seis grupos distintos, possíveis de serem observados na Figura 7.

Figura 7 - Informações utilizadas na escolha ou não do novo mercado

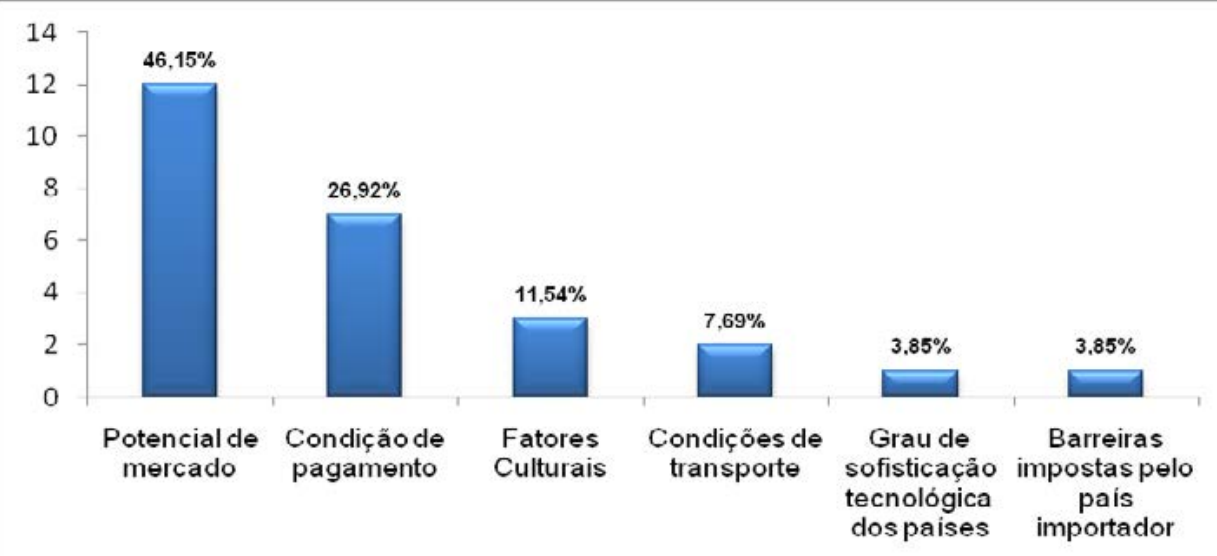

Fonte: Elaboração própria a partir de dados da pesquisa (2016). 
Segundo Fleury, Meira e Schmidt (1981), informações secundárias, ou seja, de fácil acesso, como, por exemplo, condições de transporte, grau de sofisticação tecnológica e barreiras à importação são muito utilizadas pelas empresas, porém as mais utilizadas são informações sobre os mercados com relação ao seu potencial e aos valores de importação, consideradas de fácil acesso.

A seguir, apresenta-se uma análise voltada para as barreiras organizacionais encontradas pelas empresas na sua inserção internacional.

\section{BARREIRAS ORGANIZACIONAIS NA INSERÇÃO INTERNACIONAL}

Nesta subseção, serão analisadas as barreiras organizacionais internas das empresas, relacionadas, então, à adequação da capacidade e dos recursos existentes para poder começar a atuar no mercado internacional. Essas barreiras se constituem em dificuldades e/ou obstáculos que podem prejudicar a inserção internacional. As que foram identificadas na região de estudo encontram-se abaixo, na Figura 8.

Figura 8 - Dificuldades organizacionais internas da empresa

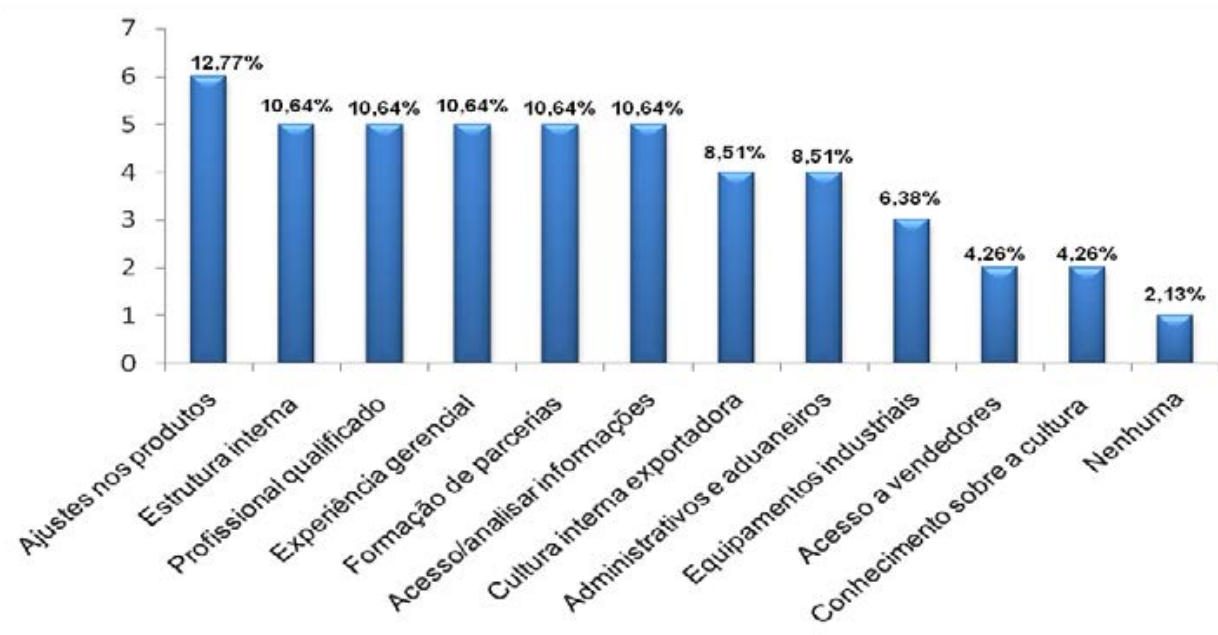

Fonte: Elaboração própria a partir de dados da pesquisa (2016). 
Vale ressaltar que as empresas tinham a possibilidade de escolher dentro dessa pergunta até cinco opções, que foram as que causaram maiores impactos a elas.

Distingue-se das respostas como maior dificuldade organizacional as mudanças e/ou ajustes nos produtos (12,77\%), que se fizeram necessárias(os) para a aceitação destes nos mercados externos e para atender às características do mercado-alvo.

Em igual proporção e relevância, estrutura interna, profissional qualificado, experiência gerencial, formação de parcerias, acesso e análise das informações sobre os mercados internacionais corresponderam, cada qual, a 10,64\% das respostas. Esses dados indicam que falta conhecimento e/ou infraestrutura interna adequada para se internacionalizar. Um profissional qualificado e adequadro a esse quadro, hoje difícil de ser encontrado, poderia eliminar várias dessas barreiras, pois traria consigo experiência e conhecimentos necessários para tornar o processo mais fácil às empresas.

É ainda possível identificar que 2,13\% das empresas, ou seja, somente uma (01), não encontrou nenhuma barreira interna. Portanto, tal empresa, que é caracteriza como sendo do setor de revestimento cerâmico, de porte pequeno, possui sua administração profissionalizada e atua no mercado internacional de 15 a 20 anos. Além disso, apresenta-se bem-estruturada para inserir seu produto no mercado estrangeiro, isso porque tomou a iniciativa de analisar o mercado externo e escolher um mercado com culturas parecidas, uma vez que essa estratégia estava no seu planejamento.

Além das barreiras internas, é possível identificar barreiras externas no processo de internacionalização. A seguir, podem ser observadas as identificadas na região de estudo.

\section{BARREIRAS EXTERNAS NA INSERÇÃO INTERNACIONAL}

Barreiras externas na inserção internacional são fatores cruciais para o sucesso ou não do processo. Há diversas barreiras externas existentes. Conforme apresentado na Figura 9, foram identificadas, no total, quatorze. Nesse questionamento, as empresas tinham a possibilidade de assinalar as cinco dificuldades mais relevantes para elas. 
Herrera (2010) informa que as empresas não possuem nenhum controle sobre tais dificuldades e, ainda, fraciona-as em barreiras de processo, governamentais e ambientais. Algumas dessas barreiras estão relacionadas com a principal dificuldade interna citada anteriormente, o ajuste em seus produtos, e são elas: exigências internacionais $(12,28 \%$ ) e cultura internacional $(5,26 \%)$, que podem influenciar diretamente nas características atuais dos produtos.

Figura 9 - Dificuldades impostas pelo ambiente externo

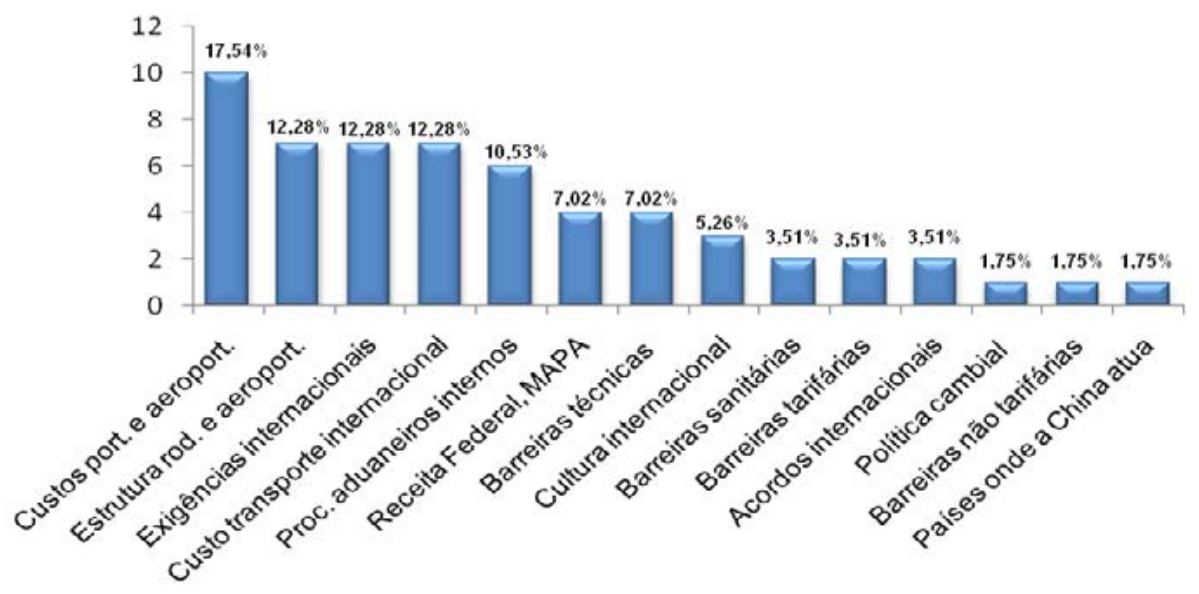

Fonte: Elaboração própria a partir de dados da pesquisa (2016).

Os custos são as principais dificuldades encontradas pelas empresas da região, destacando-se os portuários e os aeroportuários (17,54\%), seguidos pelos custos de transporte internacional (12,28\%). Tais custos estão relacionados às estruturas rodoviária e aeroportuária (12,28\%), que são consideradas ainda precárias.

\section{CONSIDERAÇÕES FINAIS}

Atualmente, com a ação da globalização, fenômeno que não se pode ignorar ou parar, diante das economias mundiais, nota-se a importância das interações comerciais entre as nações. A partir disso, observa-se no cenário econômico que a concorrência no mercado tem se intensificado, e que, para diversificar riscos e aumentar os lucros, as empresas estão buscando expandir suas vendas para outros países. 
A internacionalização é um processo que acompanha o desenvolvimento da globalização nas nações, buscando novos mercados, clientes e produtos. Entre as motivações que as organizações têm para poderem optar por tal processo, destacam-se os incentivos governamentais, a geração de lucros, a incorporação de novas tecnologias, bem como a melhora na imagem com fornecedores e entidades bancárias. Porém, como em todo processo, é possível identificar algumas dificuldades e/ou barreiras com as quais as empresas podem se deparar, como, por exemplo, os ajustes nos produtos, os custos portuários e aeroportuários.

Nesse contexto, o presente estudo buscou analisar os fatores que influenciam a tomada de decisão das empresas exportadoras do sul de Santa Catarina para o ingresso no mercado internacional.

Observou-se que a amostra das empresas pesquisadas foi caracterizada como de micro, pequeno, médio e grande porte. Elas atuam em diversos setores, com destaque para o setor metalmecânico e de revestimentos cerâmicos. Em relação às suas localizações, há destaque para Criciúma como polo industrial. As composições de capital denotam, em sua maioria, $100 \%$ nacional ou mista (majoritariamente nacional), possuindo formas de administração empresarial profissionalizada, familiar e mista.

Identificou-se que as organizações possuem diferentes experiências no mercado externo, variando de cinco a 35 anos. Essas organizações, a sua maioria, não se limitaram a exportar seus produtos para um único país, mas se limitaram a atuar nas Américas. Uma pequena proporção foi mais além, atingindo os mercados da África, da Ásia e da Europa. Foi identificado também que cada setor e cada organização possuem seu produto de destaque no mercado internacional, no entanto o que prevalece são os produtos manufaturados, que possuem valor agregado maior que o dos semimanufaturados e primários, os quais também são negociados no estrangeiro pelas empresas-alvo do estudo. A representatividade das exportações, tanto no faturamento bruto anual quanto na produção anual das empresas, é relativamente baixa, representando, no máximo, $10 \%$.

Observou-se que prevaleceu o número de empresas que tomaram a iniciativa de analisar o mercado externo. Entre os motivos que levaram as empresas a ingressarem no mercado internacional, é possível destacar as estratégias de desenvolvimento, as vantagens competitivas, a diversificação de riscos e os lucros, bem como o aumento da produtividade e dos lucros, além dos 
incentivos governamentais e pedidos inesperados advindos do exterior. Já os motivos de escolha de mercado citados pelas empresas foram a oportunidade de mercado, uma demanda visível e a existência de contatos com os possíveis importadores.

Nem todas as empresas procuraram realizar uma pré-seleção de mercado, pois se limitaram a reagir às oportunidades, enquanto outras analisaram o tamanho do mercado e/ou o grau de concorrência. Para a tomada de decisão de mercado, as organizações procuraram participar de feiras internacionais, por meio de contatos informais, experiências e por meio de alguns estudos comparativos ou detalhados. Por fim, para ter maior certeza de em qual mercado deveriam se inserir, utilizaram informações de fácil acesso, como potenciais de mercado, condições de pagamento, fatores culturais, condições de transportes.

Por fim, a dificuldade organizacional de maior destaque foram os ajustes necessários nos seus produtos, pois como cada região possui uma cultura, costumes, regras e leis diferentes. Desse modo, para poderem se inserir, as empresas necessitaram ajustar seus produtos em alguns aspectos, como, por exemplo, as embalagens utilizadas. Em relação às barreiras externas, o destaque foi para os custos e as estruturas portuárias, aeroportuárias e rodoviárias, além das exigências internacionais e barreias técnicas, sanitárias e tarifárias.

Assim, como proposta, sugere-se que empresas busquem compreender o mercado de atuação em todas as suas dimensões, para, somente a partir disso, contratar um profissional de comércio exterior qualificado ou oferecer qualificação a um bom colaborador da indústria, com a finalidade de driblar diversas barreiras impostas pelo mercado internacional. Buscar conhecer e analisar o país onde se deseja iniciar novas transações para facilitar novas negociações e evitar possíveis "gafes" que podem interferir negativamente em suas negociações. O ideal seria não apenas agir por intuição ou por causa das oportunidades, mas sim pelo conhecimento adquirido e pelas análises e pesquisas.

A pesquisa limitou-se exclusivamente à região sul de Santa Catarina. Logo, percebe-se a viabilidade do estudo em outras regiões do Estado e do País para identificar as diferentes realidades das empresas exportadoras. Como proposta para futuros estudos a partir deste tema, recomenda-se uma pesquisa com outras regiões do Estado, com a finalidade de registrar a realidade de Santa Catarina, e, por fim, do Brasil, para, desse modo, buscar novas soluções para o desenvolvimento dos setores econômicos brasileiros. 


\section{REFERÊNCIAS BIBLIOGRÁFICAS}

APPOLINÁRIO, F. Metodologia da ciência: Filosofia e prática da pesquisa. São Paulo: Pioneira Thomson Learning, 2006.

ÁVILA, C. de J. Análise do processo de internacionalização das empresas exportadoras da Associação dos Municípios da Região Carbonífera - AMREC. 2009. 122 f. Trabalho de Conclusão de Curso (Graduação em Administração de Empresas com linha específica em Comércio Exterior) - Universidade do Extremo Sul Catarinense, Criciúma, 2009.

BRASIL. Ministério do Desenvolvimento, Indústria e Comércio Exterior - MDIC. Exportação de manufaturados puxa superávit da balança comercial para US\$ 8,7 bilhões. Publicada em 14 set. 2015. Disponível em: <http://www.brasil.gov. br/economia-e-emprego/2015/09/exportacao-de-manufaturados-puxa-superavit-da-balanca-comercial-para-us-8-7-bilhoes>. Acesso em: 01 out. 2016.

BRASIL. Ministério do Desenvolvimento, Indústria e Comércio Exterior - MDIC. Empresas brasileiras exportadoras e importadoras: 2016. Sem data de publicação [on-line]. Disponível em: <http://www.mdic.gov.br/comercio-exterior/ estatisticas-de-comercio-exterior/empresas-brasileiras-exportadoras-e-importadoras>. Acesso em: 01 out. 2016.

BRITO, C. M. Estratégias de internacionalização e cooperação empresarial. In: FACULDADE DE ECONOMIA DO PORTO. Working paper $n^{\circ}$ 38. Porto: Faculdade de Economia do Porto, 1993. 28 p. Disponível em: <https://www.fep.up.pt/docentes/cbrito/estrat_intern_e_coop.pdf >. Acesso em: 29 mar. 2016.

CARNEIRO, J. M. T.; DIB, L. A. Avaliação comparativa do escopo descritivo e explanatório dos principais modelos de internacionalização de empresas. INTERNEXT - Revista Eletrônica de Negócios Internacionais da ESPM, São Paulo, v. 2, n. 1, p. 1-25, 2007. Disponível em: <http://internext.espm.br/index.php/internext/article/view/46/43>. Acesso em: 26 abr. 2016.

CARRASQUEIRA, H. B. As teorias de internacionalização no estudo de caso do maior grupo hoteleiro português. Revista Acadêmica do Observatório de Inovação do Turismo, v. 9, n. 2, p. 55-84, 2015. Disponível em: <http://www.spell.org. br/documentos/ver/40809/as-teorias-de-internacionalizacao-no-estudo-de-caso-do-maior-grupo-hoteleiro-portugues-/i/pt-br>. Acesso em: 06 maio 2016. 
DAL-SOTO, F. O processo de internacionalização de empresas brasileiras do setor de componentes para couro, calçados e artefatos. In: WORKSHOP INTERNACIONALIZAÇÃO DE EMPRESAS: Desafios e Oportunidades para Países Emergentes. São Paulo: FEA/USP, 2006. Disponível em: <http://www.unicruz.edu.br/ site/cursos/administracao/downloads/28-05-2008/artigo_fabio.pdf>. Acesso em: 23 mar. 2016.

FLEURY, A. et al. Internacionalização e os países emergentes. São Paulo: Atlas, 2007.

FLEURY, P. F.; MEIRA, R. A.; SCHMIDT, A. M. R. A decisão de exportar e a escolha de mercados de exportação: dos aspectos conceituais às práticas gerenciais nas empresas brasileiras produtoras de manufaturados. Revista de Administração de Empresas, Rio de Janeiro, v. 21, n. 3, p. 7-13, 1981. Disponível em: <http://www. scielo.br/scielo.php?script=sci_arttext\&pid=S0034-75901981000300001>. Acesso em: 13 ago. 2016.

HERRERA, W. R. S. O desafio exportador: dificuldades de inserção de micros e pequenas empresas porto-alegrenses no comércio internacional. 2010. $61 \mathrm{f}$. Trabalho de Conclusão de Curso (Graduação em Administração) - Universidade Federal do Rio Grande do Sul, Porto Alegre, 2010. Disponível em: <http://hdl. handle.net/10183/29750>. Acesso em: 02 out. 2016.

KOTABE, M.; HELSEN, K. Administração de marketing global. São Paulo: Atlas, 2000.

KUAZAQUI, E.; LISBOA, T. C. Estratégias de entrada e operação em mercados internacionais: China - Internacionalização de Empresas: teorias, problemas e casos. São Paulo: Atlas, 2009.

LOUREIRO, F. A.; SANTOS, S. A. dos. Internacionalização de empresas brasileiras. Revista de Administração da Universidade de São Paulo, São Paulo, v. 26, n. 1, 1991. Disponível em: <http://200.232.30.99/busca/artigo.asp?num_artigo=514>. Acesso em: 22 mar. 2016.

MOTTA, R. B. Decisões estratégicas no processo de internacionalização de empresas: "formas de entrada e seleção de mercado". In: ENCONTRO DE ESTUDOS EM ESTRATÉGIA, 3., São Paulo, 2007. Anais... São Paulo: ANPAD, 2007. Disponível em: <http://www.anpad.org.br/diversos/trabalhos/3Es/3es_2007/2007_3ES727. pdf $>$. Acesso em: 27 ago. 2016. 
NOSÉ JUNIOR, A. Marketing internacional: uma estratégia empresarial. São Paulo: Thomson, 2005.

PORTO, J. V. J. O processo de internacionalização de empresas exportadoras da AMREC: um estudo multicaso com enfoque nos desafios e oportunidades. 2014. 123 f. Trabalho de Conclusão de Curso (Graduação em Administração de Empresas com linha específica em Comércio Exterior) - Universidade do Extremo Sul Catarinense, Criciúma, 2014. Disponível em: <http://repositorio.unesc.net/ handle/1/2853>. Acesso em: 04 maio 2016.

SAMPIERE, R. H.; CALLADO, C. F.; LUCIO, M. Del P. B. Metodologia da Pesquisa. 5. ed. Porto Alegre: Penso, 2013.

SCHERER, F. L. GOMES, C. M. Internacionalização de empresas: perspectivas estratégicas no setor coureiro-calçadista. REGE Revista de Gestão, São Paulo, v. 17, n. 1, p. 27-44, 2010.

SERVIÇO BRASILEIRO DE APOIO ÀS MICRO E PEQUENAS EMPRESAS - SEBRAE. Critérios de avaliação das empresas: MEI - ME - EPP. Publicado em 2006. Disponível em: <http://www.sebrae-sc.com.br/leis/default.asp?vcdtexto=4154>. Acesso em: 01 out. 2016.

SERVIÇO BRASILEIRO DE APOIO ÀS MICRO E PEQUENAS EMPRESAS - SEBRAE. Santa Catarina em Números: Nova Veneza. Florianópolis: SEBRAE/SC, 2010. 118 p. Disponível em: <http://www.sebrae-sc.com.br/scemnumero/arquivo/Nova-Veneza.pdf>. Acesso em: 01 out. 2016.

ZILLI, J. C.; VIEIRA, A. C. P.; HEINZEN, M. Estratégias e Grau de Internacionalização de Empresas Transformadoras de Polímeros. Revista de Administração de Roraima, Boa Vista, v. 5, n. 1, p. 23-41, 2015. Disponível em: <http://revista. ufrr.br/index.php/adminrr/article/view/2543/1609>. Acesso em: 29 mar. 2016. 